\title{
HÉRNIA PÓS-INCISÃO EM CÃES E GATOS
}

\author{
POST INCISIONAL HERNIA IN DOGS AND CATS
}

\section{RESUMO}

A hérnia pós-incisão foi analisada quanto à prevalência e protocolo terapêutico em nove cães e seis gatos cadastrados no Hospital Veterinário da Universidade Federal de Santa Maria, RS, Brasil. Os animais apresentaram peritonite localizada que foi tratada com reposição hidroeletrolítica, antibioticoterapia, irrigação abundante da cavidade abdominal e debridamento cirúrgico. Todos tiveram evolução favorável.

Palavras-chave: eventração, evisceração, peritonite, deiscência de sutura, abdome, cirurgia.

\section{SUMMARY}

The case records of nine dogs and six cats with post-incisional hernia were managed by surgical correction at the Veterinary Hospital of the Federal University of Santa Maria, RS, Brazil, between January 1980 and June, 1998. Dogs and cats presented focal peritonitis that were treated by fluid replacement, antibiotic therapy, copious abdominal lavage, surgical debridement and reparation. This terapeutic protocol was efficient and all animals survived.

Key words: eventration, evisceration, peritonitis, wound deiscence, abdomen, surgery.

\section{INTRODUÇÃO}

As hérnias pós-incisão são adquiridas e formadas quando houver ruptura de uma cavidade, fechada por meio de cirurgia. A hérnia de incisão aguda ocorre dentro dos primeiros sete dias após a cirurgia, enquanto a crônica é notada semanas a anos mais tarde (SMEAK, 1993a). READ (1985) descreveu a hérnia de incisão como uma séria complicação da cirurgia abdominal. Pode desenvolver-se após laparotomia, principalmente na linha média ventral, a qual apresenta maior possibilidade de completa deiscência e evisceração. Segundo JOHNSTON (1990), a evisceração pode seguir-se à deiscência da sutura como resultado de cicatrização inadequada ou técnica operatória deficiente.

A prevalência da hérnia pós-incisão tem sido entre 1 e $11 \%$ em humanos e de $16 \%$ em grandes animais, dependendo da abordagem cirúrgica no abdome, de certos fatores predisponentes e da idade do paciente. Em pequenos animais, é menos comum (SMEAK, 1993b). A evisceração ou exposição dos órgãos abdominais, através da deiscência, é mais comum em hérnias agudas. $\mathrm{O}$ omento ou ligamento falciforme protrude primeiro, sendo seguido por alças intestinais. É comum lesão por automutilação, mesmo que a evolução seja de minutos. O resultado é uma severa perda de sangue e sepsia levando a choque. Um animal que apresente descarga serosangüínea pela incisão e aumento de volume local nos primeiros cinco dias após a cirurgia requer rápida ação diagnóstica e decisão corretiva (SMEAK, 1993a).

A deiscência da ferida cirúrgica decorre de várias etiologias, como falha mecânica do material de sutura, presença de infecção, desnutrição (hipoproteinemia), diminuição na síntese protéica (enfermidade hepática), aumento na perda de proteína (entero ou glomerulopatia), fibroplasia retardada (altas doses de corticosteróides), aumento na pressão intra-abdominal em sutura frouxa (HARDIE, 1996; PAVLETIC, 1996). Raramente ocorre falha na sutura por enfraquecimento ou necrose das bordas teciduais, onde elas estão ancoradas. Os sinais associa-

\footnotetext{
${ }^{1}$ Médico Veterinário, Professor Titular, Departamento de Clínica de Pequenos Animais, Centro de Ciências Rurais, Universidade Federal de Santa Maria, 97105-900 Santa Maria, RS. E-mail: raisermv@lince.hcv.ufsm.br 
dos com a deiscência dependem da camada rompida. Quando for na pele e tela subcutânea, as bordas da ferida abrem-se. Se afetar todos os planos anatômicos, sobrevém evisceração. Quando se separam apenas as camadas profundas, haverá aumento de volume, variável com o grau da deiscência e o volume de víscera insinuada. A drenagem copiosa de líquido abdominal, através da incisão, é sinal de deiscência. (HARDIE, 1996). A maioria das hérnias pós-incisionais ocorre dentro dos primeiros cinco dias após a cirurgia. É nesta fase que a ferida conta com o material de sutura como suporte primário, antes do início da síntese do colágeno (SMEAK, 1989).

A deiscência de feridas pode envolver apenas os planos superficiais e, comumente, deve-se a uma deficiente técnica operatória ou erro do cirurgião. Quando se rompem planos anatômicos profundos, há edema com flutuação na ferida. O sinal mais comum de deiscência abdominal é a descarga serosanguínea pela ferida cirúrgica e, em $50 \%$ dos casos, a etiologia é a infecção. Pode haver presença de pequena porção do epíploo, projetando-se através da sutura ou completa evisceração do conteúdo abdominal, resultando em sério traumatismo e automutilação. Nessas situações, o conteúdo abdominal deve ser protegido por compressas úmidas em salina e bandagem temporária até a intervenção cirúrgica, que constará de debridamento, remoção de tecidos desvitalizados e sutura da ferida (TAYLOR \& McGHEE, 1995).

ANDERSON (1996) cita que a solução ideal para lavar tecidos é a de Ringer lactato, a qual deve ser usada em grande volume, para diluir e remover as bactérias, sujidades e fragmentos orgânicos sem lesionar os tecidos sadios. Na presença de infecção e necrose, podem ser associados antisépticos, no entanto, o uso tópico desses ou de antibiótico solúvel não substitui um adequado debridamento cirúrgico.

BURREAU (1990) descreveu a lavagem peritoneal durante a cirurgia, procedimento que decresce as complicações pós-cirúrgicas. Segundo ele, as soluções isotônicas de cloreto de sódio ou Ringer lactato permitem eliminação mecânica de fragmentos e a diluição de elementos químicos ou sépticos, reduzindo a contagem bacteriana. As vísceras devem ser manipuladas de modo que toda a superfície seja lavada e os corpos estranhos fiquem em suspensão e sejam aspirados. O processo deve ser repetido até que o líquido drenado esteja claro e límpido.

$\mathrm{Na}$ vigência de peritonite, a prioridade no tratamento é a estabilização do paciente antes de qualquer procedimento anestésico-cirúrgico. Deve- se instituir fluidoterapia com solução de Ringer lactato, antibioticoterapia parenteral, associando cefalexina $(22 \mathrm{mg} / \mathrm{kg})$ ou ampicilina $(10 \mathrm{mg} / \mathrm{kg})$ com metronidazole $(10-20 \mathrm{mg} / \mathrm{kg})$, até definição do antibiótico apropriado. Na abordagem cirúrgica, efetuar copiosa irrigação com salina morna, evitando o uso tópico de antibiótico ou anti-séptico. O uso de drenos não é eficiente, pois em 6h sofrem obstrução por fibrina ou pelo omento e a pressão negativa inerente à cavidade dificulta a drenagem. A drenagem peritoneal aberta demanda cuidadosa monitorização, e tem risco de hipoproteinemia, anemia, hipocalemia, hiponatremia, infecção hospitalar, evisceração com automutilação, além de aumentar a formação de aderências intra-abdominais (BRAY, 1996).

A fáscia e músculo lesionados são excisados antes de fechar a área de deiscência. Os pontos de sutura não devem ficar aquém de $5 \mathrm{~mm}$ das bordas da incisão, devido à grande quantidade de colagenase presente. A sutura deve ser em pontos interrompidos (PAVLETIC, 1996). BIMONTE (1997) recomenda suturar feridas infectadas com fio de poliamida (náilon) ou ácido poliglicólico que liberam radicais bacteriostáticos.

TOGNINI \& GOLDENBERG (1998) efetuaram revisão da literatura sobre síntese da parede abdominal e consideraram que o tema ainda é controverso. Segundo os autores, atualmente, o fechamento em massa do plano peritônio-músculoaponeurótico é o mais adequado, com menor risco de complicações do que o fechamento por planos anatômicos. $\mathrm{O}$ fio de sutura deve ser inabsorvível ou de longa duração, preferencialmente monofilamentar. Quanto ao uso de sutura contínua ou em pontos separados, ainda existem divergências, ambas apresentando vantagens e desvantagens inerentes.

Considerando a morbidade das hérnias de incisão, neste artigo, são tecidas considerações sobre a conduta clínico-cirúrgica visando a contribuir para a profilaxia e terapêutica a essa patologia.

\section{MATERIAL E MÉTODO}

A prevalência de hérnia pós-incisão foi levantada no Hospital Veterinário da Universidade Federal de Santa Maria, RS, no período de janeiro de 1980 a junho de 1998. Dos prontuários foram colhidos dados relativos à anamnese, exame clínico, procedimento cirúrgico e avaliação pós-operatória.

Ao exame clínico inicial, procurou-se identificar complicações que requeressem estabilização imediata e, depois, de forma mais detalhada efetuouse exame clínico geral com apoio de exames complementares (radiográfico ou laboratorial, se necessários). Em todos os pacientes foi preparada linha 
venosa, iniciando-se a administração de solução de Ringer lactato em volume correspondente ao grau de espoliação hidroeletrolítica estimado. Nos pacientes de eventração, a cirurgia foi protelada até estabilização do animal e, nos casos de evisceração, foi feita proteção das vísceras com gaze ou compressa embebida em salina morna, e preparação do animal para cirurgia de urgência.

$\mathrm{Na}$ seqüência, foi efetuada tricotomia ampla, na área a ser abordada e anti-sepsia com iodo povidine, diluído 1:1000, com salina isotônica. Na sala cirúrgica, com o animal anestesiado, complementou-se a anti-sepsia pelo esquema álcool-iodoálcool, evitando o contato dessas soluções com as vísceras (nos pacientes de evisceração). Durante a cirurgia, os animais receberam, por via intravenosa, 10 a $20 \mathrm{ml} / \mathrm{kg} / \mathrm{h}$ de solução de Ringer lactato.

A medicação pré-anestésica foi feita com maleato de acepromazina $(0,2 \mathrm{mg} / \mathrm{kg})$ para cães e cloridrato de cetamina $(10 \mathrm{mg} / \mathrm{kg})$ em gatos. A indução anestésica foi feita com tiopental sódico $(10 \mathrm{mg} / \mathrm{kg})$ para cães ou halotano em máscara. Após intubação orotraqueal, a manutenção foi feita com halotano vaporizado com oxigênio, em circuito semi-aberto.

$\mathrm{Na}$ abordagem cirúrgica, foi feito reavivamento das bordas da ferida, que foi ampliada e os tecidos desvitalizados, coágulos, restos de fios de sutura e sujidades foram removidos por excisão, curetagem, debridamento e irrigação abundante com solução salina isotônica morna. Nos animais com evisceração e sinais de peritonite, foi efetuada irrigação com iodopolividona diluído a $0,1 \%$ em solução salina isotônica.

Quando houve comprometimento visceral efetuaram-se ressecção e/ou sutura, na dependência do grau de alteração apresentado. Antes do fechamento, a cavidade abdominal foi irrigada abundantemente com salina isotônica morna, até que a solução fosse aspirada limpa. A sutura da parede abdominal foi feita com pontos de Sultan, sendo utilizado fio mononáilon ou poliamida (náilon de pesca). Em um gato, que sofreu deiscência uma segunda vez, foram adotados pontos de Wolff posicionados a $1 \mathrm{~cm}$ das bordas da ferida, intercalados com pontos de Sultan inseridos a $0,5 \mathrm{~cm}$ das bordas.

Como protocolo terapêutico foi utilizada ampicilina sódica $(20 \mathrm{mg} / \mathrm{kg})$ e metronidazole $(20 \mathrm{mg} / \mathrm{kg})$, por via intravenosa, a partir do préoperatório imediato e continuado por uma semana, em administração oral. No pós-operatório, foi prescrito repouso, manutenção de bandagem e retorno em 7 a 10 dias para avaliação e retirada dos pontos cutâneos.

\section{RESULTADOS E DISCUSSÃO}

No período avaliado, a prevalência de hérnias na casuística hospitalar foi de 323 casos $(3,21 \%)$. Desses, $6,5 \%$ (21 casos) foram de hérnia incisional, um percentual dentro da faixa prevalente para humanos e inferior à que ocorre em grandes animais, citada por SMEAK (1993b). Os animais atendidos pelo autor ( 9 cães e 6 gatos) estão relacionados nas tabelas 1 e 2 . Como se observa, em dois cães (tabela 1) e quatro gatos (tabela 2) ocorreu completa deiscência com evisceração. Nos demais, a deiscência ocorreu no plano de junção mediano com deslocamento das vísceras para a região subcutânea que, segundo HARDIE (1996), caracteriza eventração. Essa complicação ocorreu mais em cães que em gatos e deve estar relacionada à lambedura, devido à serosidade e/ou prurido local. Como o gato é mais meticuloso quanto à higiene e a ação mecânica da língua é mais abrasiva, pode favorecer a deiscência em todos os planos de sutura.

Os sinais clínicos observados ou informados na resenha foram de aumento de volume na área operatória, nos pacientes de eventração e, em dois cães e dois gatos com evisceração, serosidade serosangüínea com exteriorização parcial do epíploo (figura 1) ou de alça intestinal que, em um cão, apresentava-se mutilada (figura 2). Foram observados, ainda, pontos rompidos ou ausentes e áreas de necrose (figura 1), sendo essa uma ocorrência que, segundo HARDIE (1996) raramente ocorre. Esses sinais clínicos são idênticos aos citados por TAYLOR \& McGHEE (1995). Em todos os casos de completa deiscência da parede, apenas a porção exteriorizada das vísceras evidenciava congestão e/ou necrose, caracterizando um processo localizado, o que infere um tempo de evolução curto, que não foi informado, pois os proprietários apenas citaram: "foi encontrado assim, e imediatamente trazido para atendimento".

Uma gata de 20 meses (tabela 2) teve nova deiscência ao quinto dia após correção, evidenciando laceração das bordas da parede abdominal. Esse caso é um exemplo de complicação que ocorre a despeito da adoção de técnica operatória apropriada e deveuse à automutilação. O paciente removeu os pontos e, segundo o proprietário, lambia insistentemente a ferida cirúrgica a despeito de tentativas de proteção com bandagem.

As hérnias ocorreram com maior freqüência entre o $5^{\circ}$ e $9^{\circ}$ dias de pós-operatório nos cães e entre o $5^{\circ}$ e $7^{\circ}$ dias nos gatos, portanto, em período superior ao de cinco dias, citado por SMEAK (1989), porém, são consideradas de evolução aguda, pois ocorreram em períodos semelhantes aos citados 
Tabela 1 - Herniorrafia abdominal. Prevalência de hérnia abdominal pós-incisional considerando a raça, sexo, idade, peso, localização anatômica, conteúdo/alteração, causa e tempo evolutivo em cães atendidos no Hospital Veterinário da Universidade Federal de Santa Maria entre janeiro de 1980 e julho de 1998.

\begin{tabular}{|c|c|c|c|c|c|c|}
\hline Raça & Sexo & Idade & $\begin{array}{l}\text { Peso } \\
(\mathrm{kg})\end{array}$ & $\begin{array}{l}\text { Localização } \\
\text { anatômica }\end{array}$ & Conteúdo / alteração & Causa / período de evolução \\
\hline Srd & $\mathrm{F}$ & $1 \mathrm{a}$ & 6,5 & $\begin{array}{l}\text { mediana retroum- } \\
\text { bilical }\end{array}$ & alça de jejuno / eventração & Ovario-histerectomia há $10 \mathrm{~d}$ \\
\hline Srd & $\mathrm{F}$ & $8 \mathrm{a}$ & 12,5 & $\begin{array}{l}\text { mediana pré- } \\
\text { retroumbilical }\end{array}$ & intestino e epíploo / eventração & celiotomia exploratória há $7 \mathrm{~d}$ \\
\hline Srd & $\mathrm{F}$ & $2 \mathrm{a}$ & 8,2 & $\begin{array}{l}\text { mediana retroum- } \\
\text { bilical }\end{array}$ & intestino e epíploo / eventração & cesareana há $2 \mathrm{~d}$ \\
\hline Srd & $\mathrm{F}$ & $18 \mathrm{~m}$ & 25,0 & $\begin{array}{l}\text { mediana retroum- } \\
\text { bilical }\end{array}$ & intestino e epíploo / eventração & Ovario-histerectomia há $24 \mathrm{~h}$ \\
\hline Srd & $\mathrm{F}$ & $6 a$ & 7,5 & $\begin{array}{l}\text { mediana retroum- } \\
\text { bilical }\end{array}$ & $\begin{array}{c}\text { alça do jejuno necrosada / } \\
\text { evisceração }\end{array}$ & cesareana há $8 \mathrm{~d}$ \\
\hline Pequinês & $\mathrm{F}$ & $7 \mathrm{a}$ & 8,4 & $\begin{array}{l}\text { mediana retroum- } \\
\text { bilical }\end{array}$ & $\begin{array}{c}\text { alça de jejuno e epíploo lacera- } \\
\text { do / evisceração }\end{array}$ & cesareana há $9 \mathrm{~d}$ \\
\hline Pequinês & $\mathrm{F}$ & $14 \mathrm{a}$ & 6,5 & $\begin{array}{l}\text { mediana retroum- } \\
\text { bilical }\end{array}$ & $\begin{array}{c}\text { alça de jejuno e epíploo / } \\
\text { eventração }\end{array}$ & $\begin{array}{l}\text { Ovario-histerectomia (pio- } \\
\text { metrite) há } 9 \mathrm{~d}\end{array}$ \\
\hline Collie & $\mathrm{F}$ & $5 \mathrm{a}$ & 30,0 & $\begin{array}{l}\text { mediana retroum- } \\
\text { bilical }\end{array}$ & $\begin{array}{c}\text { epíploo aderido às bordas da } \\
\text { ferida / eventração }\end{array}$ & Ovario-histerectomia há 7d \\
\hline Collie & $\mathrm{F}$ & $8 \mathrm{a}$ & 39,0 & $\begin{array}{l}\text { mediana pré- } \\
\text { retroumbilical }\end{array}$ & $\begin{array}{c}\text { intestino, epíploo e baço / } \\
\text { eventração }\end{array}$ & celiotomia exploratória há $8 \mathrm{~d}$ \\
\hline
\end{tabular}

Srd = sem raça definida $\mathrm{F}=$ feminino; $\mathrm{h}=$ hora $; \mathrm{d}=\mathrm{dia} ; \mathrm{m}=$ mês $; \mathrm{a}=$ ano.

por SMEAK (1993a). Em todos os animais, a celiorrafia fora efetuada com categute que estava rompido ou com nós desatados. Esse dado está de acordo com JOHNSTON (1990), o qual cita que a hérnia pós-incisional ocorre por deiscência de pontos em laparotomias medianas. Nesses casos, é possível que o nível de enzimas teciduais mais elevado, como é o caso da colagenase, citado por PAVLETIC (1996), seja um dos fatores que levaram à fragilização precoce do fio, em face de um período mais prolongado de cicatrização, que é uma característica do tecido fibroso, constituinte da linha mediana. Os casos em que os nós estavam desatados atestam a displicência do cirurgião.

Considerando que os animais relacionados nas tabelas 1 e 2: tiveram a parede abdominal suturada com categute simples (4 cães) ou cromado, quando da cirurgia primária, e os pontos incluindo porções de fibras musculares do reto abdominal; apresentaram focos de necrose nas bordas da incisão (5 animais); evidenciaram insinuação de víscera aderida na linha de sutura (4 cães) e, considerando que o tempo necessário à fibroplasia na linha mediana é ao redor de 40 dias, deduz-se que houve retardamento no processo cicatricial e deficiência na técnica operatória, corroborando com JOHNSTON (1990). Erro de técnica pela inclusão de víscera na linha de sutura e retardamento cicatricial, caracterizado pela presença de pontos de necrose que indicam focos avasculares, possivelmente em consequiência aos pontos em massa, envolvendo as fibras do músculo reto abdominal, o que prejudica a vascularização local.

O retardamento cicatricial e os fios de categute que romperam ou tiveram os nós desatados, podem explicar porque em $66,66 \%$ dos animais, nas tabelas 1 e 2, a hérnia ocorreu após o quinto dia de pós-operatório e não antes. Assim, concorda-se com READ (1985) e TOGNINI \& GOLDENBERG (1998) que, embora os fios absorvíveis sejam satisfatórios nas celiorrafias, os fios inabsorvíveis ou absorvíveis sintéticos devem ser preferidos para a rafia da linha alba, tendo em vista que o tecido fibroso precisa de sustentação por um tempo mais prolongado até cicatrizar. Considera-se, no entanto, que a rafia da parede abdominal em cães e gatos, especialmente da linha mediana, deve ser feita em plano único, envolvendo apenas peritônio e bainhas superficial e profunda, dos músculos retos do abdome, que se juntam para formar a linha alba, sem incluir 
Tabela 2. - Herniorrafia abdominal. Prevalência de hérnia abdominal pós-incisional considerando a raça, sexo, idade, peso, localização anatômica, conteúdo/alteração, causa e período evolutivo em gatos atendidos no Hospital Veterinário da Universidade Federal de Santa Maria entre janeiro de 1980 e julho de 1998.

\begin{tabular}{|c|c|c|c|c|c|c|}
\hline Raça & Sexo & Idade & $\begin{array}{c}\text { Peso } \\
(\mathrm{kg})\end{array}$ & $\begin{array}{l}\text { Localização } \\
\text { anatômica }\end{array}$ & Conteúdo / alteração & Causa / período de evolução \\
\hline Srd & M & $7 \mathrm{~m}$ & 3,5 & $\begin{array}{l}\text { mediana retroumbi- } \\
\text { lical }\end{array}$ & $\begin{array}{c}\text { alças intestinais, epíploo/ } \\
\text { eventração }\end{array}$ & enterotomia há $7 \mathrm{~d}$ \\
\hline Srd & $\mathrm{F}$ & $20 \mathrm{~m}$ & 2,5 & $\begin{array}{l}\text { mediana retroumbi- } \\
\text { lical }\end{array}$ & $\begin{array}{c}\text { alças intestinais e epíploo / } \\
\text { evisceração }\end{array}$ & $\begin{array}{c}\text { cesareana e ovariohisterecto- } \\
\text { mia há } 2 d\end{array}$ \\
\hline Srd & $\mathrm{F}$ & $3 a$ & 3,0 & $\begin{array}{c}\text { mediana retroumbi- } \\
\text { lical }\end{array}$ & $\begin{array}{c}\text { alças de jejuno e epíploo / } \\
\text { evisceração }\end{array}$ & ovario-histerectomia há $2 \mathrm{~d}$ \\
\hline Srd & $\mathrm{F}$ & $2 \mathrm{a}$ & 1,7 & $\begin{array}{c}\text { mediana retroumbi- } \\
\text { lical }\end{array}$ & epíploo / eventração & ovario-histerectomia há $8 \mathrm{~d}$ \\
\hline Srd & $\mathrm{F}$ & $1 \mathrm{a}$ & 2,7 & $\begin{array}{l}\text { mediana retroumbi- } \\
\text { lical }\end{array}$ & $\begin{array}{c}\text { epíploo / } \\
\text { evisceração }\end{array}$ & $\begin{array}{l}\text { ovario-histerectomia e colo- } \\
\text { pexia há } 4 \mathrm{~d}\end{array}$ \\
\hline Siamês & $\mathrm{F}$ & $18 \mathrm{~m}$ & 2,0 & $\begin{array}{c}\text { mediana retroumbi- } \\
\text { lical }\end{array}$ & $\begin{array}{c}\text { epíploo / } \\
\text { evisceração }\end{array}$ & ovario-histerectomia há $9 \mathrm{~d}$ \\
\hline
\end{tabular}

Srd = sem raça definida; $\mathrm{M}=$ masculino; $\mathrm{F}=$ feminino; $\mathrm{d}=\mathrm{dia} ; \mathrm{m}=$ mês; $\mathrm{a}=$ ano.

fibras dos músculos retos, ao contrário do que citam TOGNINI \& GOLDENBERG (1998). Nos casos analisados no presente artigo, onde os pontos de sutura envolviam o músculo reto, verificaram-se áreas adjacentes espessadas ou necróticas. Na rotina clínico cirúrgica do autor, não têm sido observadas deiscências relacionadas a não inclusão do músculo na rafia da linha mediana. Aliás, a reconstituição anátomo-fisiológica da linha mediana não deve incluir massa muscular. Considera-se que os pontos podem ser adaptados com margem suficiente de

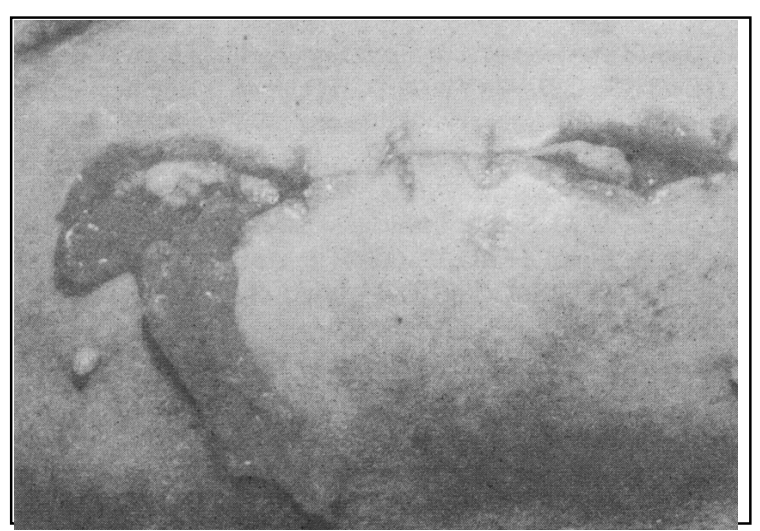

Figura 1 - Hérnia pós-incisão em gato. Evisceração parcial do epíploo em gata siamês, com 18 meses de idade, submetida à ovario-histerectomia há 9 dias. tecido fibroso para prevenir a ação da colagenase, citada por PAVLETIC (1996).

Uma séria complicação da hérnia de incisão, citada por TAYLOR \& McGHEE (1995), é a evisceração seguida de automutilação (figura 2a), conforme foi observado em uma cadela de 6 anos (tabela 1). No caso, a ressecção dos segmentos alterados seguida de enteroanastomose término-terminal permitiram reconstituição da mesma. Embora o animal apresentasse necrose em uma das alças, não evidenciava sinais de toxemia, nem de perda sangüínea significativa, que são a consequiência da automutilação, segundo SMEAK (1993).

A remoção dos pontos de sutura rompidos, excisão dos tecidos desvitalizados, higienização (figura 2b) e ressecção parcial de vísceras comprometidas (epiploectomia e enterectomia parcial seguida de enteroanastomose) e irrigação abundante com salina morna, além da fluidoterapia e administração de antibiótico por via parenteral, compuseram o protocolo transoperatório e seguiram os cuidados citados por READ (1985), BURREAU (1990) e BRAY (1996). Especificamente em relação ao controle da peritonite, foi efetuado debridamento cirúrgico das aderências e lavagem exaustiva da cavidade peritoneal, conforme orientou ANDERSON (1996), porém, com iodopolividona diluído em solução salina de cloreto de sódio $0,9 \%$ na proporção de 


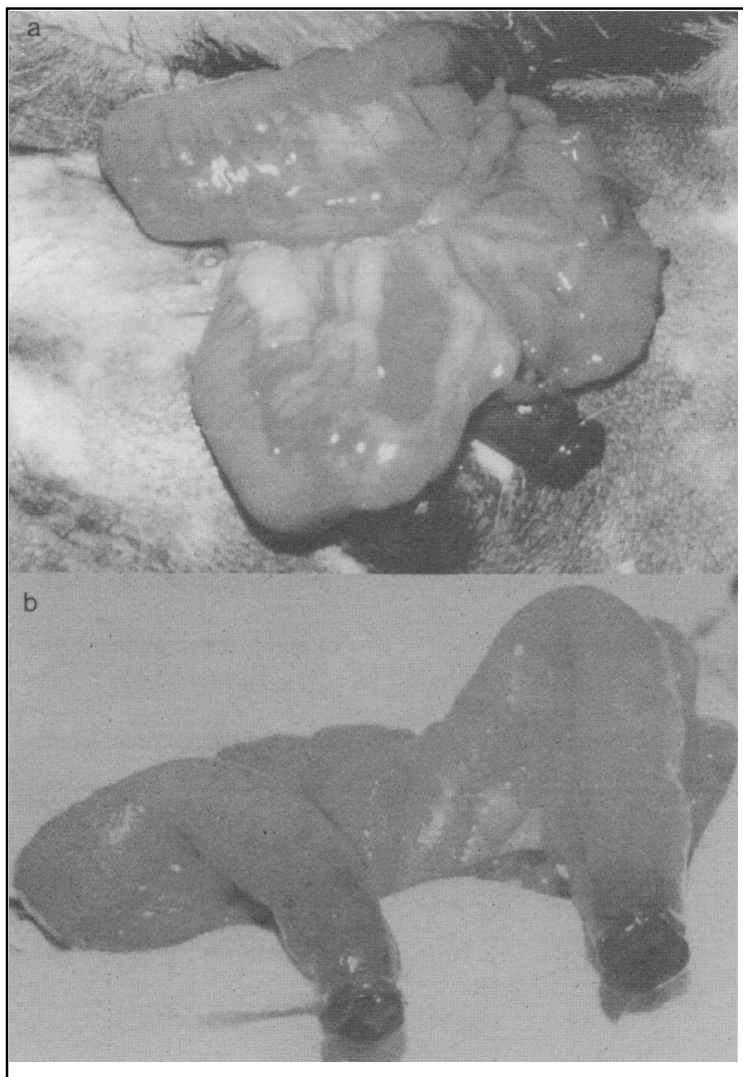

Figura 2 - Hérnia pós-incisão em cão. Evisceração de alça intestinal, com automutilação em cadela sem raça definida, 6 anos de idade, submetida à operação cesareana há 8 dias. a) apresentação clínica ao encaminhamento; b) apresentação após higienização, prévio a ressecção e enteroanastomose.

1:1000, repetidas vezes. O uso dessa associação, e não do Ringer lactato recomendado por ANDERSON (1996), nos casos de evisceração, não deixou evidências de irritação devido à baixa concentração do iodo e parece ter colaborado no controle à contaminação local, pois os animais tiveram excelente recuperação. No uso desse anti-séptico, deve-se evitar o produto cuja apresentação comercial possua, associado ao iodo, substância saponificante, como o lauril-éter sulfonato de sódio, que é irritante às mucosas. Como a peritonite foi restrita às vísceras exteriorizadas, os animais não manifestavam sinais sistêmicos de infecção e, face às complicações e desvantagens dos drenos citadas por BRAY (1996), foi efetuada celiorrafia sem adaptação dos mesmos.

A associação de ampicilina com metronidazole, citada por BRAY (1996), é o protocolo antibacteriano parenteral utilizado no Hospital Veterinário da UFSM como rotina, há mais de 20 anos, nos casos de suspeita de contaminação ou infecção por anaeróbicos, e tem apresentado excelente resultado.
Em todos os animais, a sutura foi efetuada com poliamida, conforme recomendou BIMONTE (1997), devido à contaminação ou infecção presente. Tanto o náilon cirúrgico como o náilon de pesca esterilizado foram tolerados sem evidência de complicação pós-cirúrgica. Quanto ao modelo de sutura, deu-se preferência à síntese interrompida, pois a possibilidade de eventual deiscência fica minimizada com esse modelo, particularmente em animais já predispostos à evisceração, embora TOGNINI \& GOLDENBERG (1998) citem que os dois modelos possam ser utilizados.

\section{CONCLUSÃO}

A hérnia pós-incisional é comum a partir do quinto dia após a cirurgia e deve-se à técnica operatória deficiente, comprometimento da vascularização local, uso inadequado de fios e de nós que desatam, tipo de sutura e presença de infecção. Na celiorrafia, a sutura dos músculos retos deve ser restrita às suas lâminas interna e externa e que o fio seja monofilamento inabsorvível ou absorvível de longa duração.

\section{REFERÊNCIAS BIBLIOGRÁFICAS}

ANDERSON, D. Wound management in samll animal practice. In Practice, v. 18, n. 3, p. 115-128, 1996.

BIMONTE, D. Reacciones de materiales de sutura usados em cirurgía veterinaria. Veterinaria, v. 33 , n. 133, p. 12-14, 1997.

BRAY, J. Diagnosis and management of peritonitis in small animals. In Practice, v. 18, n. 9, p. 403-413, 1996.

BURREAU, P. Lavage péritonéal peropératoire. Le Point Vét, v. 22, n. 130 , p. 23(451)-31(459), 1990.

JOHNSTON, D.E. Care of accidental wounds. Vet Clin North Amer: Small Anim Pract, v. 20, n. 1, p. 27-46, 1990.

HARDIE, E.M. General abdominal surgery. In: LIPOWITZ, A.J., NEWTON, C.D., CAYWOOD, D.D. et al.. Complications in small animal surgery. Baltimore: Williams \& Wiilkins, 1996. Chp. 12, p. 333-342.

PAVLETIC, M.M. Surgical management of traumatic abdominal wounds. In: CONGRESS OF THE AMERICAN ANIMAL HOSPITAL ASSOCIATION, 1996. San Antonio, Texas. Scientific Proceedings... Denver, Co: American Animal Hospital Association, 1996. 556 p. p. 298-299.

READ, R. Cranial abdominal hernias. In: SLATER, D.H. Textbook of small animal surgery. Philadelphia: Saunders, 1985. Cap. 58, p. 862-869.

SMEAK, D.D. Management and prevention of surgical complications associated with small animal abdominal herniorraphy. Problems in Vet Med, v. 1, n. 2, p. 254-267, 1989.

Ciência Rural, v. 29, n. 4, 1999. 
SMEAK, D.D. Abdominal hernias. In: SLATER, D.H. Textbook of small animal surgery. 2. ed. Philadelphia: Saunders, 1993a. Chap.36. p. 433-454.

SMEAK, D.D.Abdominal hérnias. In: BOJRAB, M.J. Disease mechanisms in small animal surgery. 2. ed. Philadelphia: Lea \& Febiger, 1993b. Cap. 15. p. 98-102.
TAYLOR, R., McGHEE, R. Manual of small animal postoperative care. Baltimore: Williams \& Wilkins, 1995. Cap. 4: Postoperative care of the wound: $36-47$.

TOGNINI, J.R.F., GOLDENBERG, S. Síntese da parede abdominal: sutura contínua ou com pontos separados? Revisão da literatura. Acta Cirúrgica Brasileira, v. 13, n. 2, p. 116$122,1998$.

Ciência Rural, v. 29, n. 4, 1999. 